\title{
EDITORIAL \\ Intellectually disabled and impaired people serving sentences in conventional correctional facilities: some considerations
}

In 1991, a report by the Spanish Ombudsman on the legal situation of mental patients in Spain brought to light the unfortunate reality of mental patients and intellectually disabled inmates hosted in correctional facilities of all sorts, most of them with no judicial control, with no date of application ${ }^{1}$.

1995's Criminal Code, by establishing a limit on the duration of security measures, led to the revision of such situation. Studies and assessments were carried out. The overwhelming number of affected inmates was striking. Part of the media echoed this reality which was renamed as "the map of shame".

I remember that most of the efforts were aimed at supporting the situation of these people or their prompt discharge.

This was not my main concern but answering the question: How could this happen?

The search took me even further: from the mistakes and the traps of the judicial and police system, to the deficiencies of social and healthcare systems, the miseries of the economic system and educational deficits.

This supports 1986's WHO Ottawa Declaration, which stated that the fundamental conditions and resources for health are:

"Peace, shelter, education, food, income, a stable eco-system, sustainable resources, social justice and equity. Improvement in health requires a secure foundation in these basic prerequisites ${ }^{2}$ ".

The presence or absence of these factors directly entails the preservation or loss of health in general and of mental health in particular.

Some people, due to genetic, ideological, emotional, social or family causes are more or less resilient to impacts of life. Those whose health is threatened and who suffer from a serious mental disorder, face a chronic condition for which few social and health resources are committed.
For our purpose, the worst situation is when people are not aware of their disease. When there is no awareness, patients refuse any type of care and treatment, therefore entailing disruptive situations and altercation, mostly in streets and homes, which lead to criminal procedures, mostly due to family violence or assault related crimes.

The probability for these patients to serve sentences in Conventional Correctional Facilities is very high for the following reasons:

- The promptness of so called "expedious trials", entails a more difficult identification of the disorder. An immediate delivery of sentence is common in this type of urgent procedures, with the prior agreement of the accused.

- Sentences for family violence related crimes entail restraining orders which are failed to comply with hence entailing another crime, a violation of the previously stated sentence. With regard to this point the newly reformed Penal Code introduces a moderation for the disabled (amended Art. 48-1).

The truth is that from 2006, the Prison Administration began to make visible its concern for this painful reality. Good evidence for this can be found in the study "Mental Health in Correctional Facilities".

As a consequence of this consideration and impulse, in 2009 the Comprehensive Care for Mental Patients in Prison Protocol was implemented, and further amended in 2012.

On the other hand, Instruction 19/2011 of the General Secretariat of Penitentiary Institutions established to implement Articles 20, 21 and 22 of the Royal Decree $840 / 2011$ as of June $17^{\text {th }}$, clearly states a concern for these patients to receive the appropriate support once outside prison to avoid exclusion and their return to the criminal justice system. This entails a fortunate and radical change of approach. 
Until now, what legal texts evidenced was that these people were judicially determined to be mentally incompetent, hence the communications and referred testimonies to the Public Prosecutor as to assess the adoption of this measure.

It is not incapacity mandates that mentally disabled and mental patients need. First of all, they should be granted the necessary support to lead a dignified life once released. Some will count on their families; others will need the support of public or private institutions and organisms.

Release should be prepared at least six months in advance, aiming at the coordination between families and social and healthcare organisms.

Instruction 19/2011 of the General Secretariat of Penitentiary Institutions states the following:

"Penitentiary intervention is not limited to the penitentiary space and time, inherently it demands a close connection to rehabilitation public and private entities and permanent forward-thinking, with a special attention to family networks, community treatment and tuition resources, and the participation of third-sector agencies, as to obtain improved therapeutic benefits from their contact with the criminal justice system".

The preparation for release includes the following aspects:

1. Managing the appropriate documents to access social and healthcare provisions, if necessary.

Hence, it is the right time to process, when applicable, aid and support included in the so called "Dependency Law".

Currently, it is impossible to access social provisions without this recognition.
Assessment should be carried out within the correctional facility itself or by competent organisms from each Autonomous Community, upon application from the interested party or, if they lack the ability of doing so, upon application from Prison Social Services who, in this case, would act as de-facto guardians (Art. 304 Civil Code).

2. The establishment of appropriate channels or even agreements with both public and third-sector agencies.

As an example of good practice, a Collaboration Agreement was approved in March 24 2014 between the General Secretariat of Penitentiary Institutions and the Andalusia Public Foundation for the social inclusion of mental patients (FAISEM in Spanish) aimed at including inmates suffering from mental disorders in the "employment" resources of the aforementioned foundation (while in prison) and in their "housing" resources (upon release).

This is the way to address the stigma of the unfortunate ones who are disabled and imprisoned.

Fernando Santos Urbaneja

Prosecutor of the Provincial Court of Córdoba

\section{BIBLIOGRAPHIC REFERENCE}

1. Ombudsman Office. 1991 Annual Report. [Internet]. Madrid: Congress of Deputies; 1992 [cited 2015 May 27]; 76-95. Available from: https://www.defensordelpueblo.es/wpcontent/ uploads/2015/05/INFORME1991informe. pdf

2. World Health Organization. The Ottawa Charter for Health Promotion [Internet]. Ottawa: PAHO; 1986. [cited 2015 May 27]. Available from: http:// www1.paho.org/spanish/ HPP/OttawaCharterSp.pdf 